\title{
La escritura infinita. Personajes multiplicados y anhelos de inmortalidad en la cuentística de Carlos Liscano
}

Quanto piú procedo, piú vado convincendomi che non esiste frontiera. Non esiste, io sospetto, frontiera, almeno nel senso che noi siamo abituati a pensare [...] Probabilmente varcherò il limite senza accorgermene neppure.

(Dino Buzzati, «I sette messaggeri») Las obras afectadamente escritas que cien años ba se publicaron, apenas se balla boy quien las quiera leer, cuando las de los bombres elocuentes del mismo tiempo con diligencia se buscan, con mucho gusto se leen, con veneración se alaban.

(Gregorio Mayans, Oración que exborta a seguir la verdadera idea de la elocuencia española)

\section{A modo de presentación}

El propósito del presente estudio reside en analizar una sección de la producción cuentística del escritor uruguayo Carlos Liscano (Montevideo, 1949), concentrando la atención en su recopilación Oficio de ventriloquia I, que incluye y reúne los relatos publicados entre 1981 y $2011^{1}$. El objetivo del análisis,

1 La extensa producción literaria de Carlos Liscano comienza a estructurarse ocho años después del día de su encierro, posteriormente a una etapa en la que el futuro escritor se había dedicado al estudio de las matemáticas. Dentro de ese marco literario es posible establecer dos macro-ámbitos: un primero que incluye la obra narrativa y un segundo en que caben los trabajos ensayísticos del autor. En el amplio apartado ficcional se pude identificar una tríplice repartición: un primer nivel que incluye a las siguiente novelas: Memorias de la guerra reciente (1988), La mansión del tirano (1992), El camino de Ítaca (1994), La ciudad de todos los vientos (2000), El furgón de los locos (2001), y Lecteur inconstant suivi de Vie du corbeau blanc (2011). Un segundo nivel abarca la cuentística, de la que forman parte las siguientes recopilaciones de relatos: El método y otros juguetes carcelarios (1987), Agua estancada y otras historias (1991), El 
en particular, consiste en examinar de qué manera el escritor concibe, en el relato «La historia interminable», una reflexión intratextual con su propia obra narrativa y establece también un diálogo intertextual con «La Biblioteca de Babel», de Jorge Luis Borges.

El cuento se coloca dentro de la línea conceptual que marca toda la producción narrativa de Liscano, caracterizada por el vínculo -como forma de continuo existencial- entre la escritura y la vida misma. El trabajo de contar y el oficio de vivir se superponen en los textos del escritor montevideano, en tramas protagonizadas por seres que suelen reflexionar sobre la tarea de escribir ficciones cuyo argumento se niega a dejarse atrapar. Se trata de una relación entre la vida y la escritura que Ignacio Bajter ha señalado con acierto en su prólogo a la novela Escritor indolente (2014): «Hay que asumir la existencia de Liscano como punto de partida, como entidad fija. La primera parte de Escritor indolente es un diario y como tal un registro híbrido del oficio de vivir. Las 75 entradas son el verdadero prólogo del libro» (Bajter, 2014: 9-10).

Así como la novela en forma de diario es un campo abierto y destinado a ser poblado de palabras, en un relato como «La historia interminable» existe también la posibilidad de especular con la ficción y de plantear un cuestionamiento articulado en torno a los dos motivos siguientes:

a) la conversión del quehacer del escritor en un proceso de reencuentro consigo mismo, gracias al cual el «yo» intenta entregarse al oficio de contar y lo hace pluralizándose en una multiplicidad de instancias creadoras. En la tarea de salir de la espiral en que ha caído el escritor indolente, el camino de autoconocimiento de sí mismo se realizaría precisamente a través de la escritura. Hemos definido esta línea estética como un «diálogo intratextual» justamente porque el eje conceptual en que se apoya la producción narrativa de Liscano pone de manifiesto una obsesión recurrente, la de escribir sobre el acto mismo de la escritura, como forma de recuperación de la unidad del ser mediante la creación ficcional. Esta preocupación, que recorre transversalmente tanto la ficción pura como los enayos del escritor, se consolida, en particular, en dos

charlatán (1994), Ejercicio de ventriloquia (2011). Finalmente, el tercer nivel de la producción ficcional del escritor se completa con dos recopilaciones de historietas: El Tarumba (2003) y Nulla dies sine linea, (2006) y tres libros de poemas: ¿Estará nomás cargada de futuro? (1989), Micellanea Observata (1995), La sinuosa senda (2000). El segundo macro-ámbito de la obra de Liscano es, como se ha dicho, el de la no-ficción, en el que se puede incluir los ensayos $E l$ lenguaje de la soledad (2000) y El escritor y el otro (2007), la investigación periodística Ejercicio de impunidad (2004), una selección de artículos sobre idioma español titulada Lengua curiosa (2003) y un ensayo-entrevista, Conversaciones con Tabaré Vázquez (2003). 
textos La Ciudad de todos los vientos, del año 2000, y El escritor y el otro, de 2007, verdadero ensayo novelado que reflexiona sobre el oficio de escribir y la complejidad de la creación ante la hoja en blanco.

b) el segundo macro-motivo presente en el relato remite al vínculo entre, por una parte, la mortalidad del ser humano y su desaparición física del mundo, y por otra, el anhelo de «producir» nuevos creadores. En el cuento, estos nuevos creadores remiten a un giro autobiográfico por el que su nacimiento ocurre lejos de toda trascendencia: veremos que se trata de seres que se plasman a partir de la voluntad escritural de un progenitor-escritor y que se van multiplicando de forma exponencial reflejando un deseo de perduración y de aspiración al absoluto.

\section{Un diálogo con Borges: existir, o sobrevivir, por la escritura}

Bien es sabido que en «La Biblioteca de Babel», Borges recupera la lectura del cosmos que proponía Blaise Pascal según el cual el universo, es decir, un espacio infinito, vendría a adquirir las formas de una esfera cuyo centro está en todas partes y la circunferencia en ninguna: a partir de esta base lógica, el relato borgesiano describe la Biblioteca como «una esfera cuyo centro cabal es cualquier hexágono, cuya circunferencia es inaccesible» (Borges, 2013: 90). Las referencias explícitas a la infinitud, a un centro ubicado en todas partes y a una circunferencia inaccesible remiten a una de las claves de la visión borgesiana de la literatura: el escribir es un ejercicio de pura fabulación mediante el cual el sujeto creador intenta provocar una suspensión distanciadora de los referentes espacio-temporales en los que el relato se produce y se transmite.

Esta suspensión distanciadora de todo lo actual y presente se logra a través de la inclusión en la ficción de rasgos destemporalizados que dificultan (o impiden) la ubicación de lo narrado en un cronotopo definido. La imaginación del escritor apela sí a imágenes tradicionales, pero las combina con alusiones a una dimensión ancestral, donde se vislumbra una correspondencia continua en que sagrado y profano dialogan entre sí y donde se manifiesta una superposición entre lo humano y lo natural. Esta combinación lleva a identificar una relación entre la escritura y una suerte de Memoria Universal, que detenta un poder ritual apoyado en leyendas y saberes arquetípicos, hasta desembocar en lo que Saúl Yurkievich en su ensayo «Borges/Cortázar: mundos y modos de la ficción fantástica» define como 
fantástico ecuménico, cuya ubicua fuente es la Gran Memoria, la memoria general de la especie. Borges se remite a los arquetipos de la fantasía, al acervo universal de leyendas, a las historias paradigmáticas, a las fábulas fundadoras de todo relato, al gran museo de los modelos generadores del cuento literario. Para Borges lo fantástico es consustancial a la noción de literatura, concebida ante todo como fabulación, como fábrica de quimeras y de pesadillas, gobernada por el álgebra prodigiosa y secreta de los sueños, como sueño dirigido y deliberado (Yurkievich, 2007: 157).

En el relato de Liscano, la escritura es también una «fábrica de quimeras» porque le proporciona al anciano protagonista la posibilidad potencial (o la simple esperanza ilusoria) de resignificar su presencia en el mundo mediante «un sueño dirigido y deliberado», que consiste en la ambición de una fabulación infinita. Este objetivo debería lograrse, en las expectativas del hombre, a través de la multiplicación de las instancias creadoras: «Será así: pienso dos personajes. Cada uno inventará otros dos y los narrará. Los últimos en aparecer inventarán cada uno dos y se ocuparán de narrarlos. Así siempre, durante sesenta y cuatro veces» (Liscano, 2011: 30). Precisamente en este deseo de multiplicación de las instancias creadoras reside, asimismo, esa «álgebra prodigiosa» de la narrativa borgesiana, un álgebra por la que el personaje de Liscano apunta al crecimiento exponencial de creadores, con los que a su vez ambiciona reducir la precariedad del asentamiento humano sobre lo real.

Para analizar más en detalle el vínculo que existe entre el lenguaje y la posibilidad de que este le permita al ser humano perpetuarse en el tiempo, volvamos al examen del título del relato borgesiano; los dos sustantivos empleados (biblioteca, Babel) remiten a un valor semántico esencial, que les atribuye el papel de clave interpretativa del texto: al lector le toca descifrarlo o ponerse en expectativa por un significante. «La Biblioteca de Babel», en una primera instancia, hace referencia a la Torre biblica, es decir a un lugar donde Yabveb decidió confundir el lenguaje de todos los habitantes de la tierra. En este sentido, podría afrmarse que «la historia funciona como metáfora del no bay metalenguaje de Lacan, o en otras palabras no hay Otro del Otro» (González Aja, 2008). En esta óptica, el vínculo que se establece entre el lenguaje y la bibilioteca (como cofre donde el lenguaje se guarda bajo la forma de textos escritos) remite a una percepción polisémica del nombre Babel: no se estaría aludiendo solo a la ciudad, sino también a un nombre que implica la letra, es decir, el lenguaje. Y 
el lenguaje es lo que le permite al ser humano perpetuarse en el tiempo, y que le otorga la posibilidad de huir del olvido a través de la escritura como forma de permanencia, tal como sugiere Jaime Rest en su ensayo «El universo de los signos»; sostiene Rest que «en la producción de Borges el destino del hombre y del mundo radica, con fatalidad irreversible, en transformarse en materia verbal, en componente de ficción. La condición humana nos lleva inexorablemente a ser olvidados o a convertirnos en literatura» (Rest, 1992: 17).

Esta operación de conversión del ser en literatura se intenta lograr, en el cuento de Liscano, a través de un procedimiento de mise en abîme que se relaciona con los motivos de la identidad personal, de la construcción de la figura del doble y de la representación de la infinitud: la abismación se produce porque la mano que escribe, es decir, la mano de las instancias creadoras, una vez multiplicadas, es -a su vez- una mano (d)escrita (por el protagonista).

En otro ensayo sobre la literatura de Borges, titulado «Soñar el sueño», Yurkievich hace hincapié en otros dos rasgos de la escritura borgesiana, analizando la relación entre literatura y sueño, por una parte (la literatura como sueño proyectado en la escritura), y la multiplicación de los creadores de la palabra, por el otro. Lo eterno, para Borges, reside en la capacidad para trasladar la materia del sueño a los estados de la vigilia; asimismo, es en los sueños donde suele generarse la materia para la reiteración de figuras de ficción que, a su vez, crean ficción; en particular sostiene Yurkievich, que

la literatura es sueño y - por ende, una suerte de eternidadprolongado en la vigilia. Para Borges, fundamentalmente toda la literatura proviene del sueño, primordial y principal potencia fabulosa. Borges suele en sus escritos retomar sus propios sueños, como aquél de la torre circular donde el prisionero que se le parece escribe un poema ilegible sobre un hombre que en la celda contigua escribe un poema ilegible sobre un hombre ... (Yurkievich, 2007 b: 181).

En el texto de Liscano, la multiplicación de los creadores de la palabra no es el resultado de un sueño, pero ambas dinámicas se inscriben dentro de un «infinito» a través del cual el proceso de creación se abisma. El infinito de Borges - como se describe de forma emblemática en «Las ruinas circulares»- es justamente un «infinito circular», en cuya estructura los magos se sueñan unos a otros para poder existir; el infinito de Liscano, en cambio, es un «infinito exponencial». 
Este «infinito exponencial» al que apunta el personaje de «La historia interminable» es sin duda el resultado de la ausencia de tiempo (la muerte se aproxima), pero también del deseo del escritor de colocar su relato en el plano de un desafío en un tablero de ajedrez, tal como el mismo Liscano admite: «Yo pensé un lector que durante toda la vida se prepara para escribir la obra y, al final, se queda sin tiempo. Entonces encuentra una solución: dejar la norma con la que se podría escribir una obra interminable usando la potencia de 2. [...] Una norma tomada de la leyenda del ajedrez» ${ }^{2}$.

Sobre la base de un crecimiento exponencial apoyado en la potencia de 2, el proyecto del protagonista de «La historia interminable»-al consistir en la creación de una serie de personajes que se van multiplicando en instancias creadoras - aproxima el proceso de multiplicación a la idea de infinitud; esta dinámica -aplicada al proceso de creación literaria- puede interpretarse según la doble lectura que se propone a continuación.

En primer lugar, el texto parece recorrer el camino trazado por Nietzsche a propósito de la muerte de Dios, y plantea una poética de la creación que borra la presencia de lo divino. La «mano que escribe» (es decir, la mano de los seres venideros encargados de multiplicar la palabra) nace por la voluntad de otra «mano que escribe». A su vez, este método de (pro)creación remite a una estética que enlaza con una vertiente del arte plástico de la segunda posguerra: el desdoblamiento y la repetición, en particular, representan elementos idiosincrásicos en la obra pictórica de Maurits Cornelis Escher; el pintor holandés «concibe un método fantástico de procreación, evitando la vías de reproducción naturales, donde no existe una jerarquía superior a la raza humana: la voluntad genésica ya no es patrimonio exclusivo de la divinidad» (Martínez Pérsico: 2010: 214)33.

2 La cita procede de una serie de breves conversaciones que mantuve con Carlos Liscano a mediados de marzo de 2016 por medio del correo electrónico. El fragmento citado, en particular, es parte de un correo del escritor del 17 de marzo de 2016.

3 Que los motivos de la repetición y de la multiplicación estén muy presentes en la obra pictórica de Escher lo confirma la estructura de un cuadro como Print Galery, lienzo de 1956 (ver figura 1). En la obra el pintor holandés utiliza una serie de ampliaciones progresivas que provocan la relación siguiente entre las figuras: el visitante que aparece a la izquierda del lienzo está ampliado cuatro veces si lo ponemos en relación con los cuadros y las figuras humanas que se evidencian en el lado derecho, más abajo. Y el mismo cuadro que aparece en el lado izquierdo, arriba, a su vez, está ampliado cuatro veces en relación al visitante. La relación se repite de forma sucesiva de tal manera que la cornisa que enmarca la figura de la mujer asomada a la ventana resulta ampliada 256 veces en relación a las columnas que la sustentan. 
La segunda modalidad de lectura del texto de Liscano dialoga precisamente con esta «voluntad genésica» que ya no es patrimonio exclusivo de la divinidad, y convierte la multiplicación de las instancias creadoras en una exigencia de perduración del ser humano; a través de la lógica por la que la «mano que escribe» nace por la voluntad de otra «mano que escribe», el personaje de Liscano apunta a crear un corpus literario potencialmente infinito, mediante el que alcanzar la «inmortalidad por la escritura»4.

Este segundo punto es el que más concierne a nuestro enfoque puesto que en esta dinámica, de nuevo, el relato de Liscano establece un diálogo intertextual con «La Biblioteca de Babel», en cuya trama «la única perduración cierta de que pueden disfrutar quienes vivieron en etapas pretéritas consiste en acceder a la frágil pero obstinada subsistencia nominal que ha quedado asentada en un texto» (Rest, 1992: 18). La subsistencia nominal a la que alude Rest, se hace manifiesta -en el texto del escritor uruguayo- en el deseo de perpetuarse a través de la escritura, y refleja por ende una voluntad de infintud: el personaje de Liscano anhela un objetivo que es una forma de transgresión absoluta mediante el lenguaje. El anciano, al usar la lengua para crear fábulas destinadas a multiplicarse, ratifica implícitamente la relación entre el lenguaje y el anhelo humano hacia la superación de sus propios límites.

La transgresión que subyace al afán de (pro)crear se expresa en el deseo de un infinito que se expande no según el vector dimensional sino temporal, y que debería alcanzarse a través del lenguaje; se trata de un recorrido que Slavoj Žižek resume así: «es el lenguaje en sí mismo lo que empuja nuestro deseo más allá de los límites adecuados, transformándolo en un deseo que contiene el infinito, elevándolo a una compulsión absoluta que nunca puede satisfacerse» (Žižek, 2015: 83). Una de las posibles claves interpretativas del relato reside precisamente, a nuestro juicio, en la naturaleza de este deseo compulsivo de perpetuarse, y en la naturaleza de su detonante. En este sentido, sería útil detenerse en la dificultad para el ser humano de sustraerse a la tentación de un «deseo desviado» (que en nuestro caso sería la multiplicación ad infinitum de las instancias creadoras). Jaccques Lacan usaba el término objet petit à (donde el adjetivo petit se refiere a la preposición $\grave{a}$ ) para referirse a un algo que

4 El tema del creador que crea a otro creador es otro eje central de la estética pictórica de Escher, tal como se observa en la obra Drawing hands, de 1948 (ver figura 2). En el cuadro, el pintor holandés se detiene en mostrar los engaños de la creación artística y literaria: cada una de las dos manos representadas está pintando a la otra. Ambas manos, a su vez, están apoyadas sobre una hoja de papel que forma parte de la misma superficie plana en que está contenido el conjunto de la obra. 
persiste como esencia intangible responsable del «deseo excesivo». El deseo del protagonista de perdurar más allá de la muerte por medio de la escritura se debe precisamente a ese «objeto no muerto etéreo, el objeto sobrante que causa el deseo en su aspecto excesivo y desviado. Uno no puede librarse de este exceso, pues es consustancial al deseo humano como tal» (Žižek, 2015: 83). Este deseo muy profundamente humano, en el relato se manifiesta bajo la forma de un intento de usar el lenguaje para evitar el olvidos.

\section{Los narradores y la estilización del contexto}

El narrador del relato de Borges ha estado dedicando su juventud a la búsqueda de un libro, un volumen imposible, capaz de cifrarlo todo: «Como todos los hombres de la Biblioteca, he viajado en mi juventud: he peregrinado en busca de un libro, acaso del catálogo de catálogos» (Borges, 2013: 90). En el momento en que se desarrolla la narración, sin embargo, el hombre ya es un anciano que está preparándose para morir y que ha comprendido que esa imposibilidad se funda en la lógica matemática de la teoría de los conjuntos: apoyada en la noción de pertenencia, la teoría no solo prevé que los propios conjuntos pueden imaginarse a su vez como elementos de otros conjuntos, sino que pone de relieve -y esto es lo que importa para nuestro enfoque- la imposibilidad de encontrar algo que nunca ha existido; así lo expresa el protagonista: «Ahora que mis ojos casi no pueden descifrar lo que escribo, me preparo a morir a unas pocas leguas del hexágono en que nacì» (Borges, 2013: 90). Cuando llegue su hora, el hombre sabe que alguien tirará su cuerpo por una baranda: su cuerpo se corromperá, su búsqueda inútil será olvidada y su caída (también en términos de olvido) será infinita.

Observemos que en el relato borgesiano el acto locutivo está a cargo del que podríamos definir como el «narrador-personaje»: desde su peculiar posición autobiográfica -ya sabemos que se encuentra al final de su vida- el hombre desea relatar la historia de la Biblioteca. Su objetivo parece consistir en traspasar el conocimiento que tuvo en torno a la biblioteca, con el fin de que en el futuro las generaciones venideras sepan quién fue, de qué manera y dónde se desarrolló su vida.

5 En el quehacer del escritor, sobre todo cuando este escritor ha vivido la experiencia de la represión y de la cárcel, la línea que separa la escritura como intento de sustraerse al olvido de la simple obligación social puede ser muy fina, tal como el mismo Liscano observa en Escritor indolente: «Si el escritor decide contar su experiencia para evitar el olvido, y así cumplir con su obligación social, puede llegar el momento en que sienta que está reduciendo una historia colectiva intrasmisible a formas narrativas espurias. Sentirá el fastidio de parecerse a un burócrata, sentirá que está escribiendo un informe» (Liscano, 2014: 50). 
Ahora bien, en la primera parte del relato de Liscano el protagonista también es descrito como un hombre anciano, que ha llegado al final de su vida y que «sabe que va a morir. Es un viejo, lector a perpetuidad, sentado en un sillón. Mira por la ventana del sanatorio. Repasa libros que ha leído» (Liscano, 2011: 30). Hasta ese momento, este antihéroe es solo un vetusto, ávido lector. Sin embargo, el personaje de «La historia interminable» siente con amargura que debería haber construido a lo largo de su vida una obra monumental: «ahora está que se muere. Entonces resuelve cortar caminos. En lo que queda, lo poco que le queda, hará lo que no escribió» (Liscano, 2011: 30).

Si tuviéramos que analizar el lugar y la colocación biográfica desde las que el hombre manifiesta su proposición, solo podríamos afirmar que se encuentra en su sillón, en un sanatorio cuyos rasgos no se describen, en una ciudad de la que no se proporcionan referencias, en un país no identificado, y que ha sido siempre y solo un escritor in fieri, incapaz de liberarse de la «jaula del enunciado imposible». Si bien el hombre no se prepara todavía a morir, ni se encuentra cerca de algún edificio de simbología oculta, como es el hexágono del personaje borgesiano, la puesta en escena del relato de Liscano recupera los moldes que propone Borges: en ambas ficciones no hay señal de localización ni de singularización de la trama, es decir, el escenario que funciona como «espacio de la historia» es el resultado de una estilización del contexto y de los contenidos, con el objetivo de que el texto se vuelva fábula.

El relato - en tanto que mera fábula- no presenta interferencias en lo actual ni en las circunstancias contingentes: de este modo, la historia se aisla de todo tiempo y de todo espacio concretos. En suma, tanto el Borges de «La Biblioteca de Babel», como el Liscano de «La historia interminable» remiten a la figura de un escritor que

cuando asienta sus historias en ambientes contemporáneos, [tiene] una visión arcaizante, canónica, [que] atenúa todo rasgo de modernidad, de modo tal que ninguna señal actualice, localice o singularice la puesta en escena, para que ninguna contravenga la estilización propia de una fábula ejemplar exenta de las intromisiones de la actualidad, de un modelo sin incidencia de lo accidental, que por no confundirse con lo circunstancial y circundante, resulta apto para repetirse en cualquier tiempo y cualquier lugar (Yurkievich, 2007a: 158).

Si en ambos relatos la definición del cronotopo se apoya en una atemporalidad deliberada, en el texto de Liscano el tiempo mismo se condensa y se dilata 
sin respetar las coordinadas lógicas, de manera tal que el protagonista puede afirmar: «Haré el último esfuerzo, el que no hice, al que debí dedicar medio siglo. Dejaré una obra inacabable, pero perfectamente construida» (Liscano, 2011: 30). El afán de condensar en un último breve periodo de la vida una escritura que nunca se hizo concreta antes nos permite recuperar otra información clave: nos referimos a la confirmación de que el protagonista de Liscano -hasta llegados sus últimos días- no ha sabido volcar al papel en blanco los conocimientos y la inspiración derivados de sus variadas lecturas. En el apartado que sigue nos proponemos analizar las razones por las que el hombre no se asomó siquiera a empezar esa obra monumental que tenía pensado escribir.

Para acercarnos a una respuesta posible, que remite a la idea de «Novela impedida» propuesta por Macedonio Fernández en Museo de la novela de la eterna, observamos cómo el discurso ideológico tradicional coloca la idea de inmortalidad en una dimensión vinculada con el Bien y asocia, en cambio, al Mal lo perecedero y la mortalidad. La lógica que subyace a esta percepción reside en asociar la raíz del Mal con la resignación a la mortalidad humana. Precisamente los motivos de la mortalidad y de la desaparición del ser están enlazados con el deseo de crear nuevos autores que se multiplican de forma exponencial: este anhelo representa un deseo que «contiene el infinito» y que pretende reaccionar a la aniquilación del ser.

Liscano plantea aquí no solo una visión filosófica acerca de la condición humana que da sentido a la búsqueda de literaturización de la existencia, sino que reflexiona también sobre la relación entre el sujeto creador y sus manifestaciones. Lo dicho converge en el hecho de que el procedimiento de creación de las instancias creadoras remite a la identificación de la escritura literaria como un metalenguaje que refleja la orientación estética de su autor: metalenguaje precisamente en tanto en cuanto es una forma de creación artística que habla del arte y que pone de manifiesto la postura estético-ideológica del autor. Se hace patente aquí otro eje clave de la poética de Liscano: nos referimos a la presencia dúplice del motivo del doble y de un proceso genésico que sustrae a lo divino el rol de demiurgo, tal como resume Rosario Peyrou cuando identifica los temas esenciales del escritor montevideano en

la búsqueda de un centro que dé sentido a la vida, el motivo del camino y el viaje, [...] un cierto misticismo sin Dios, la desesperación frente a las dificultades del lenguaje para transmitir una experiencia auténtica. Y el tema del doble, que recorre su obra, y que se imbrica con fuerza en esta tensión 
que tienen sus personajes entre el movimiento perpetuo y la necesidad de un puerto definitivo (Peyrou, 2001: 28).

Ahora, la alusión al tema del doble se añade a la definición de la «escritura literaria como metalenguaje» para significar que los textos se convierten en reflejos multiplicados del discurso autorial o, en otras palabras, para confirmar que constituyen el punto de contacto entre la poética individual del autor y el contexto social de referencia. Esta dinámica de interacción entre la identidad autorial y su manifestación en la escritura lleva Liliana Swiderski a sostener que los textos ofrecen «marcas discursivas que emanan de la posición del autor en calidad de tal, a las que llamaremos autoremas [...]. Son índices de autor en los que resulta perceptible el enlace con el contexto social» (Swiderski, 2012: 37).

En el relato de Liscano los autoremas no vendrían a ser «personajes escritores» que intervienen directamente en la composición de la obra primigenia; no pertenecerían, en suma, a esa categoría de personalidades literarias que firman el texto, como en el caso de los heterónimos o apócrifos que pueblan las páginas de Fernando Pessoa o Antonio Machado. Su intervención en la escritura será posterior, así que parece más adecuado al contexto del relato atribuir a las instancias creadoras (destinadas a multiplicarse) la categoría de contraimágenes del autor, es decir verlas como «figuras que operan como proyecciones metafóricas innominadas» (Swiderski, 2012: 38). El personaje de «La historia interminable» parece hacer alarde de una firme convicción acerca de la fidelidad de sus autoremas a su programa de escritura; esto es, el hombre propone un esquema evolutivo de tipo matemático por el que sus proyecciones escriturales, al emanar de la posición del autor, sabrán manifestar fielmente sus opiniones, sus programas de escritura, y su ideario.

Nos encontramos ante un caso de autorepresentación autoral por la cual el autor crea el diseño de «personajes escritores» que repiten los modelos discursivos y estéticos de su creador. Si se considera el autorema como una «unidad discursiva delimitada (y, en consecuencia, explícita y susceptible de ser discriminada de otras), que da cuenta de una praxis» (Swiderski, 2012: 38), podría entonces afirmarse que en el personaje se condensan dos tendencias opuestas: por una parte, una primera que ya hemos analizado y que remite al proceso de gestación de los nuevos sujetos creadores: esto ocurre, ya sabemos, según un método de procreación fantástica apoyado en simetrías matemáticas. Por otra parte, las páginas del cuento estarían consolidando - una vez más- la centralidad en la obra de Liscano de una línea estética que se ha difundido en la literatura contemporánea occidental, y que enlaza no solo con la dificultad de escribir, sino 
también con la tentación de «dejar la escritura». Veremos en el apartado que sigue de qué manera esta tendencia se aplica al caso que nos ocupa.

\section{Escribir, perdurar, jugar}

Reinaldo Laddaga en su estudio «La tentación de no escribir: el escritor como informante», analiza este fenómeno, y-al evidenciar este rasgo en la escritura de otros narradores hispanoamericanos del ocaso del siglo XX como Roberto Bolaño, César Aira o Fernando Vallejo- subraya cómo una gran cantidad de ellos «tienen en su centro a uno o a varios personajes afectados por la tentación de no escribir. Algunos de estos personajes ceden a esta tentación; otros no lo hacen pero sienten que posiblemente deberían» (Laddaga, 2011: 89) ${ }^{6}$.

Ya se ha comentado que en el relato de Liscano el personaje muestra su interés por llevar a la forma escrita su proyecto solo en sus horas postreras; sin embargo, hasta ese momento es solo una figura que ha mostrado a lo largo de su vida una conciencia literaria muy exigente (como lector) y que, pese a su larga frecuentación del texto escrito (siempre como lector), no escribe. Este perfil se aproxima al del narrador que Enrique Vila-Matas pone a cargo de una serie de reflexiones sobre la escritura en Bartleby y compañia: el narrador de Vila-Matas afirma que desde hace un tiempo se está dedicando al «mal endémico de las letras contemporáneas», que consiste - según afirma- en «la pulsión negativa o la atracción por la nada que hace que ciertos creadores, aun teniendo una conciencia literaria muy exigente (o quizás precisamente por eso), no lleguen a escribir nunca» (Vila-Matas, 2000: 12).

Ahora bien, la presencia de esa tentación de no escribir a la que aluden Laddaga y Vila-Matas, y que en el personaje de Liscano se había manifestado en una imposibilidad creativa a lo largo de toda su vida, remite a una posible «lectura a la inversa» de la asociación tradicional que vincula la inmortalidad al bien y la mortalidad al mal. Si recuperamos la propuesta que plantea Žižek de invertir la ideología común sobre esta asociación, podríamos asociar el mal a la idea de persistencia y por ende percibirlo como «algo que amenaza con volver

6 La reflexión de Reinaldo Laddaga se apoya en la observación empírica aplicada a textos narrativos publicados en la America hispana y lusófona entre finales del siglo XX y la primera década de la actual centuria; Laddaga incluye en el ámbito de los personajes que caen en la tentación de no escribir a los héroes ficcionales de Roberto Bolaño (sobre todo los de Los detectives salvajes y de 2666), de César Aira (los personajes de las novelas Varamo y Paménides), de Fernando Vallejo (La rambla paralela), Mario Levrero (La novela luminosa), Ena Lucía Portela (Djuna y Daniel) o -en el contexto brasileño- los que pueblan la entera producción narrativa de João Gilberto Noll. 
siempre, una dimensión espectral que sobrevive por arte de magia a su aniquilación física y continúa acechándonos» (Žižek, 2015: 84). Volvamos a «La historia interminable» y a la naturaleza de su protagonista para averiguar qué tipo de utilidad puede tener para nuestro enfoque la lectura de Žižek: ya se ha comentado cómo el personaje del relato pretende alcanzar la inmortalidad mediante la escritura, si bien nada ha estado escribiendo durante toda su vida; ahora, en punto de muerte, siente que la resignación a su propia mortalidad sería «algo malo». Y sin embargo, según la línea propuesta por Žižek, se podría interpretar que la victoria del bien sobre el mal reside precisamente en la capacidad de morir, de desaparecer sin dejar huella.

Esta victoria del bien a través de la muerte consistiría en la liberación del hombre de la amenaza continua de un mal que está siempre al acecho. Es decir, la victoria del bien sobre el mal sería la capacidad de

recuperar la inocencia de la naturaleza, de encontrar la paz en la liberación de la obscena infinitud del mal. [...] Un hombre poseído por alguna fuerza maligna [...] finalmente se ve liberado de ella y entonces recupera la serena belleza de su forma normal y muere en paz. Por ello Cristo debe morir; los dioses paganos que no pueden morir son encarnaciones del mal obsceno (Žižek, 2015: 84).

Si se aplican las observaciones de Žižek al relato de Liscano, la reflexión de fondo (es decir, la que celebra la obsesión por el conocimiento absoluto, el deseo de abarcarlo todo, conocerlo todo y narrarlo todo) puede trastocar la interpretación clásica (inmortalidad = bien) y proponer otra por la que la victoria del bien sobre el mal reside precisamente en la capacidad de morir, de desaparecer sin dejar huella. En este sentido, «La historia interminable» parece ofrecer una reelaboración crítica de esta obsesión: es verdad que la identidad del escritor debería multiplicarse (en sus planes) en una infinitud de autoremas creadores, pero esa misma identidad está condenada a difuminarse después de la muerte, proponiendo otra causa de olvido: la desaparición se debería precisamente al hecho de que nadie puede abarcar toda esa obra monumental que los autoremas han ido construyendo. La liberación del hombre de la amenaza continua de un mal que está siempre al acecho sería, en suma, una liberación involuntaria.

Obsérvese cómo la percepción de no poder ser leído está lúcidamente presente en la mente del anciano protagonista: desde la ventana del sanatorio, 
el hombre ya prevé su fracaso y afirma: «Sé que no habrá lector para toda mi obra. Una vez alguien no encontró tantos granos de trigo como el número de mis personajes» (Liscano, 2011: 30). Esta conversión en nada del escritor se debería paradójicamente a la búsqueda de un exceso de infinitud, como consecuencia de la multiplicación ad infinitum de las instancias creadoras.

Este círculo vicioso remite de nuevo y con toda evidencia al relato borgesiano y al rasgo infinito y totalizador de la biblioteca de Babel; en el cuento de Borges la primera reacción cuando se proclamó que la Biblioteca abarcaba todos los libros, fue de «extravagante felicidad». El estado de euforia colectiva se debió -en ese primer momento- a que esa disponibilidad garantizaría a los seres humanos el acceso a un tesoro que Borges define «intacto y secreto». Sin embargo, el lector va aprendiendo que, con el pasar del tiempo, a la desaforada esperanza, sucedió un estado de depresión colectiva debido a la certidumbre de que «algún anaquel en algún hexágono encerraba libros preciosos y de que esos libros preciosos eran inaccesibles, pareció casi intolerable» (Borges, 2013: 94). El andamiaje psicológico representado por la esperanza totalizadora (que puede reflejarse bien en perseguir el Catálogo de Catálogos, bien en escribir una obra literaria monumental destinada a ser inagotable e interminable) se derrumba precisamente ante la infinitud.

Queda, entonces, la posibilidad de una reinterpretación del deseo postrero de escribir por parte del personaje de Liscano: nos referimos a la escritura (y a la creación de otros seres capacitados para esa tarea) como una necesidad interior vinculada con la dialéctica entre lo serio y lo lúdico. En este sentido, Carl Jung alude a la

actividad del juego de la fantasía por una necesidad interior, sin constricción por parte de las circunstancias y tampoco de la voluntad. Es un juego serio. Y sin embargo es siempre un juego, pues es visto desde afuera, desde la conciencia, es decir, desde el punto de vista del juicio colectivo; no obstante [es] un juego nacido de una necesidad interior (Jung, 1999: 134).

Esta interpretación enlaza con la actitud del protagonista del relato por el carácter ambiguo inherente a todo lo que es creativo: afirma Jung que si el juego se desarrolla en sí mismo, sin que se pueda generar nada duradero ni vital, entonces será siempre y solo un juego; en el caso opuesto, podría considerarse un trabajo creativo. El personaje de Liscano, encerrado en el sanatorio, al final de su vida, puede verse como el espíritu creador que juega con lo que ama (los libros, la palabra escrita, el lenguaje). 
Puesto que «cada actividad creadora cuyas potencialidades permanecen ocultas a la multitud puede ser considerada un juego» (Jung, 1999: 134), podría leerse su deseo de creación ad infinitum como la manifestación de la exigencia de sacar a la luz estas potencialidades ocultas. En el momento en que el texto comience a tomar forma y sus personajes-autoremas empiecen a surgir de su lápiz, podrá finalmente desaparecer, tal como afirma en la última línea del cuento: «Una vez alguien no encontró tantos granos de trigo como el número de mis personajes. Creo que así uno puede morirse» (Liscano, 2011: 30).

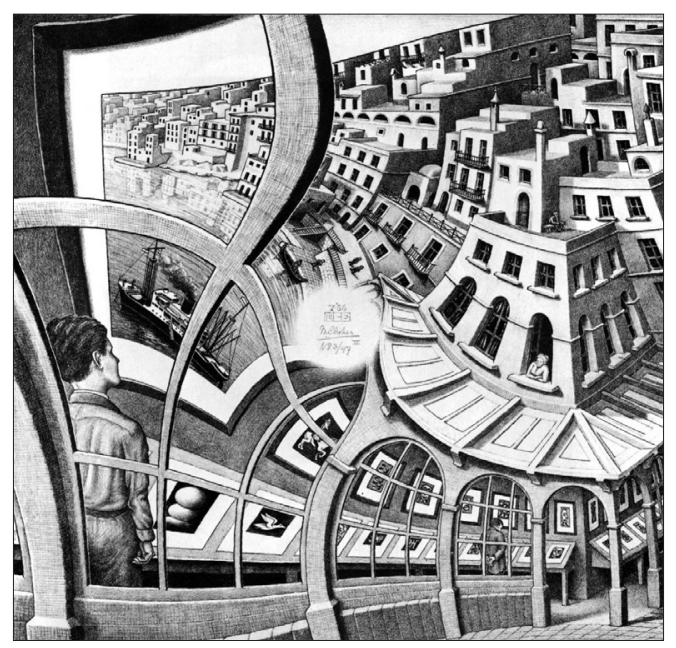

Fig. 1 Print Galery (1956)

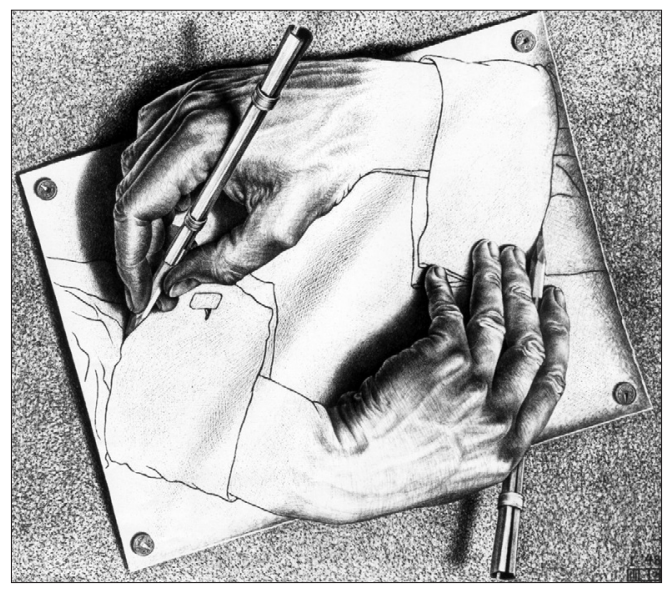

Fig. 2 Drawing bands (1948) 


\section{Bibliografía}

Bajter, I. (2014): «Novela-comarca inventada para lo imposible». En: Carlos Liscano, Escritor indolente. Montevideo: Irrucciones Grupo Editor, 9-15.

González Aja, C. (2008): «La Biblioteca de Babel (Jorge Luis Borges)» - Contribución al seminario de investigación «Del sujeto del significante al sujeto del goce», impartido por Miquel Bassols durante el curso 2006-2007: http://www.scb-icf.net/nodus/contingut/article. php art $=286 \&$ rev $=38 \& p u b=1(09-03-2016)$.

Borges, J. L. (2013): Ficciones. Barcelona: Random House Mondadori.

Jung, C. G. (1999): Tipi psicologici. Torino: Bollati Boringhieri editore (primera edición en alemán: Psycologische Typen, Zürich, 1967).

Liscano, C. (2011): Oficio de ventriloquia I. Montevideo: Planeta.

Liscano, C. (2014): Escritor indolente. Montevideo: Irrupciones Grupo Editor.

Laddaga, R. (2011): «La tentación de no escribir: el escritor como informante». En: Francisca Noguerol Jiménez, María Ángeles Pérez López et al. (eds.), Literatura más allá de la nación. De lo centrípeto y lo centrífugo en la narrativa bispanoamericana del siglo XXI. Madrid: Iberoamericana/ Vervuert, 89-102.

Martínez Pérsico, M. (2010): «Analogía de la invención: M. C. Escher y Jorge Luis Borges». Cartapbilus. Revista de investigación y Crítica Estética, 7-8, 212-218.

Peyrou, R. (2001): «Carlos Liscano». En: Alberto Oreggioni (ed.), Nuevo Diccionario de Literatura uruguaya, II. Montevideo: Ediciones de la Banda Oriental, 27-29.

Rest, J. (1992): «El universo de los signos». En: Ana María Barrenechea et al., Borges y la crítica. Buenos Aires: Centro editor de América Latina, 7-40.

Swiderski, L. (2012): Pessoa y Antonio Machado. Autores en tensión. Los autoremas como enlaces entre literatura y sociedad. Mar del Plata: EUDEM.

Vila-Matas, E. (2000): Bartleby y compañia. Barcelona: Tusquets.

Yurkievich, S. (2007a): «Borges / Cortázar: mundos y modos de la fición fantástica». En: Saúl Yurkievich, A través de la trama. Sobre vanguardias literarias y otras concomitancias. Madrid: Iberoamericana/Vervuert, 155164 . 
Yurkievich, S. (2007b): «Soñar el sueño». En: A través de la trama. Sobre vanguardias literarias $y$ otras concomitancias. Madrid: Iberoamericana/ Vervuert, 181-183.

Žižek, S. (2015): Sobre la violencia. Seis reflexiones marginales. Barcelona: EspasaPaidós. 
Giuseppe Gatti Riccardi

Guglielmo Marconi University

\section{The endless writing exercise. Multiplied characters and wishes of immortality in the short story production of Carlos Liscano}

Keywords: Carlos Liscano, uruguayan contemporary short narrative, Oficio de ventriloquia I, immortality by writing, creation of creative instances

The aim of our analysis is to study a section of the narrative production of the Uruguayan writer Carlos Liscano (Montevideo, 1949), focusing on the short story La bistoria interminable in the collection of the author's stories Oficio de ventriloquia $I$, published between 1981 and 2011. We seek to understand, on the one hand, how the writer conceives an intratextual conection between his own narrative work and "La historia interminable" and, on the other hand, how he establishes an intertextual dialogue with Borges' La biblioteca de Babel. La bistoria interminable maintains a thematic continuity with Liscano's entire narrative production with the leitmotiv of how to match life with writing and does so in two ways. First it creates a series of characters who in turn multiply infinitely, which can be read as reflecting a human need to create a potentially infinite literary corpus as means of attaining "immortality through writing". Second, the short story offers a reflection on the human obsession with absolute knowledge and the desire to know everything and to narrate everything and indeed seems to present a critical re-elaboration of this obsession; in the story, the identity of the writer dissipates after his death, precisely because nobody can cover all his work. Writing, in this case, becomes merely a "store of experiences" that no one can use. 
Giuseppe Gatti Riccardi

Univerza Guglielmo Marconi

\section{Neskončno pisanje. Pomnožene osebe in želje po nesmrtnosti v kratkih zgodbah Carlosa Liscana}

Ključne besede: Carlos Liscano, urugvajsko sodobno pripovedništvo, Oficio de ventriloquia I, nesmrtnost skozi pisanje, ustvarjanje kreativnib instanc

Predmet pričujoče analize je študija enega izmed segmentov pripovedne produkcije urugvajskega pisatelja Carlosa Liscana (Montevideo, 1949), pri čemer se avtor osredotoča na zbirko Oficio de ventriloquia I, ki združuje kratke zgodbe, objavljene med letoma 1981 in 2011. V prispevku želi raziskati, na kakšen način pisatelj v kratki zgodbi »La historia interminable« vzpostavi intertekstualno refleksijo o lastnem pripovednem opusu, pa tudi intertekstualni dialog s kratko zgodbo »La Biblioteca de Babel« Jorgeja Luisa Borgesa. Zgodba ohranja tematsko kontinuiteto s pomočjo konceptualne makrolinije, ki zaznamuje celotno Liscanovo pripovedno produkcijo: iskanje načina, kako bi življenje sovpadlo s pisanjem.

Avtor poskuša pokazati, da zgodba »La historia interminable« sproža dvojno prevpraševanje. Najprej gre za ustvarjanje niza likov, ki se eksponentno množijo v kreativnib instancab; pomnoževanje do neskončnosti - aplicirano na proces literarnega ustvarjanja - je mogoče brati kot nujo po obstanku človeka, ki skuša ustvariti potencialno neskončen literarni korpus, da bi dosegel »nesmrtnost skozi pisanje«. Druga raven pa je refleksija o obsesiji z absolutnim védenjem, željo, da bi zajel in ubesedil vse; tako se zdi, da Liscanova zgodba ponuja ponovno predelavo kritike te obsesije, saj se pisateljeva identiteta po njegovi smrti razprši prav zato, ker nihče ne more zaobjeti njegovega dela $\mathrm{v}$ celoti. Pisanje, če povzamemo, se torej postavi v vlogo »shrambe za izkušnje«, ki jih nihče več ne more uporabiti. 